\title{
Punching Faces and Publishing Papers: a Review of Jonathan Gottschall's The Professor in the Cage: Why Men Fight and Why We Like to Watch
}

\author{
Michael N. Pham ${ }^{1}$
}

Published online: 12 August 2015

(C) Springer International Publishing 2015

We are living in a peaceful period of human history (Pinker 2011). Yet, our minds retain remnants of our violent evolutionary past. Even though violence is "unbecoming" of a refined, civilized man, many of us have a thirst for witnessing violence, as evidenced by the popularity of contact sports and, in particular, by the meteoric rise of mixed martial arts (MMA). (Jonathan Gottschall 2015), the author of The Professor in the Cage: Why Men Fight and Why We Like to Watch, delivers an unapologetically honest account of his experiences as a mixed martial artist.

This book is not a collection of research findings on human combat - most of which lack descriptions of the raw, human experience of violence. Nor is it a diary of one fighter's brutish adventure into combat - which is often void of scientific analysis. Rather, it is an eloquent combination of both: Gottschall describes his first-hand experiences involving combat—inside and outside the cage - with a scientific eye. In other words, this book provides unique insights on "the other side of the table" that the scientist, the cage fighter, or the layperson would otherwise never experience.

Gottschall describes the importance of the pre-fight stare down, noting that "if you lose the prefight staring duel, you are well on your way to losing the actual fight" (p. 54). To someone who has never experienced combat and who is unfamiliar with research on combat, the stare down seems like a trivial spectacle to promote a fight. But this is a naïve conclusion. Among many non-human species, ritualized combat is an escalation of increasingly dangerous stages, each of which provides a combatant with information about the opponent's

Michael N. Pham

mnpham@oakland.edu

1 Oakland University, Rochester, MI, USA "formidability" - or strength and skill. For example, there are three stages of ritualized combat between two battling sierra dome spiders Neriene litigiosa (Watson and Field 2004). The spiders will "size up" one another by spreading their front legs. They will pluck the spider web with their other legs to demonstrate their formidability (stage 1 ). If the spiders still cannot assess which of the two is more formidable, then, they proceed to wrestle each other (stage 2). If the fighters still cannot decide which combatant is more formidable, then, they will bite each other-sometimes resulting in death (stage 3). Each subsequent stage is more dangerous than the previous stage. If at any stage one spider is clearly outmatched by the other, then the weaker spider will not escalate and will forfeit the contested resources to the winner. It is not difficult to appreciate how humans might follow a similar script: One man insults another man at a pub. They turn and stare each other down. Each man spreads his arms laterally to his side while verbally provoking the other. If neither man retreats, then they shove each other. If the escalation continues, then punches are thrown. If the insult was particularly egregious, then lethal weapons may be deployed. All of this begins with the pre-fight stare down (i.e., stage 1), during which each fighter advertises his confidence in his own formidability. Indeed, among professional MMA athletes, the fighter who smiles more during a pre-fight stare down - which is an expression of reduced hostility in a fight - is more likely to lose (Kraus and Chen 2013).

Gottschall notes that "beneath all the wild diversity of human sporting events, there is a shared underlying structure and purpose. Sports, just like gazelle wrestling, are always about finding reasonably safe, rule-bound ways for people to demonstrate their physical prowess and mental toughness to others" (p. 140). Here, again, Gottschall demonstrates his sophisticated understanding of the scientific literature. It is no coincidence that many MMA organizations across several cultures forbid punches to the groin or throat. Humans abide 
by what Romero et al. (2014) term "the implicit rules of combat." Humans categorize the context of a fight (e.g., play fighting, status contest, warfare, anti-exploitative), and each context is associated with a different set of acceptable and respectable combative tactics. In other words, a "dirty tactic" in one context may not be as dirty in a different context. For example, imagine how acceptable is it for a man to punch his opponent in the groin (a) if the fight was a sanctioned MMA match, (b) if two young adolescents were play-fighting, or (c) if the opponent broke into the man's home at night and tried to kill his family. Sports competitions are designed so that competitors can honestly advertise their formidability and secure higher status upon victory, while avoiding unnecessary injury. Humans recognize the purpose of sports competitions, and our perceived acceptability of a tactic depends on whether that tactic serves the goal of the fight context. Among the Yanomamo, men compete against other men from a different village "with each man taking multiple turns hitting and being hit....and the hitting will escalate from chest punches to slap with the flat side of an axe" (p. 181). Such competitions - like MMA - are designed for competitors to demonstrate their superior formidability over opponents while avoiding the costs of war.

Despite the refinements of civilized society, our ancestral minds continue to recognize the significance of combat. Even Gottschall, who is a Distinguished Research Fellow in the English Department at Washington \& Jefferson College, admits that "when I've hit someone this hard, I've felt bad and apologized. And always, secretly, I've felt a little good...to physically dominate another man is intoxicating" (p. 205). This is not a case study on psychopathy. Rather, it is a reflection of how the mind evolved in human ancestral environments - a setting in which the victor in combat reaped significant reproductive benefits. Fighting for “honor wasn't some trivial thing; it was precious coin that bought the best things in life. And if this coin was devalued, a man's prospects - and the prospects of his entire family-were devalued as well" ( $p$. 15). In our modern society, and particularly for an academic, Gottschall's comments are socially risky, yet they are admirably and refreshingly honest.

In conclusion, given Gottschall's unique experiences as a scholar and a fighter, this book has something for every reader. The sports fans can learn about the underlying mechanisms that explain why fighters do the things they do, thereby enriching their experience when watching or participating in combat sports (and, for that matter, in any sport). The academic can experience how research translates to an honest, realworld account, something that cannot be appreciated from reading research articles that describe the statistically averaged behaviors of individuals in a group. And the casual reader can learn the importance and reach of scientific research, even with regard to human combat - a realm that appears quite disparate from academia.

\section{References}

Gottschall, J. (2015). The professor in the cage: why men fight and why we like to watch. New York: Penguin Press.

Kraus, M. W., \& Chen, T. W. D. (2013). A winning smile? Smile intensity, physical dominance, and fighter performance. Emotion, 13, 270-279.

Pinker, S. (2011). The better angels of our nature: why violence has declined. New York: Viking.

Romero, G. A., Pham, M. N., \& Goetz, A. T. (2014). The implicit rules of combat. Human Nature, 25, 496-516.

Watson, P. J., \& Field, S. A. (2004). Costs increase as ritualized fighting progresses within and between phases in the sierra dome spider, Neriene litigiosa. Animal Behaviour, 68, 473-482. 